\title{
Measurement of multi-wall carbon nanotube penetration through a screen filter and single-fiber analysis
}

\author{
Journal Article \\ Author(s): \\ Wang, Jing; Kim, Seong Chan; Pui, David Y.H. \\ Publication date: \\ 2011-10 \\ Permanent link: \\ https://doi.org/10.3929/ethz-b-000039409 \\ Rights / license: \\ In Copyright - Non-Commercial Use Permitted \\ Originally published in: \\ Journal of Nanoparticle Research 13(10), https://doi.org/10.1007/s11051-011-0415-y
}




\title{
Measurement of multi-wall carbon nanotube penetration through a screen filter and single-fiber analysis
}

\author{
Jing Wang $\cdot$ Seong Chan Kim $\cdot$ David Y. H. Pui
}

Received: 16 February 2011 / Accepted: 6 May 2011/Published online: 19 May 2011

(C) Springer Science+Business Media B.V. 2011

\begin{abstract}
In this study, we carried out experiments to study penetration of airborne carbon nanotubes (CNTs) through a screen filter. An electrospray system was employed to aerosolize suspensions of multi-wall CNTs. The generated airborne CNTs were characterized by electron microscopy, and the length and diameter were measured. In the filtration experiments, the challenging CNTs are classified by a differential mobility analyzer. Monodisperse CNTs with the same electrical mobility were then employed to challenge the screen filter. Penetration was measured for CNTs in the range of 100-400 nm mobility diameters. The results showed that the CNT penetration was less than the penetration for a sphere with the same mobility diameter, which was mainly due to the larger interception length of the CNTs. We compared the modeling results using single-fiber filtration efficiency theories with the experimental data, and found that the effective interception length
\end{abstract}

J. Wang $(\bowtie)$

ETH Zurich, Institute of Environmental Engineering, 8093 Zurich, Switzerland

e-mail: jing.wang@ifu.baug.ethz.ch

J. Wang

Empa, Analytical Chemistry, 8600 Dübendorf,

Switzerland

S. C. Kim · D. Y. H. Pui

Particle Technology Laboratory, Department

of Mechanical Engineering, University of Minnesota,

Minneapolis, MN 55414, USA can be approximated by the CNT aerodynamic diameter multiplying a scaling factor. A hypothesis is proposed to understand the observation.

Keywords Emission controls · Filtration · Control technology - Pollution control equipment . Environmental and health implications

\section{Introduction}

Carbon nanotubes (CNTs) are being used in structural composites for sporting equipment, conductive plastics, electron field emitters, semiconductor devices, etc. Concerns have been raised about the environmental and health impact of CNTs (Wick et al. 2007; Helland et al. 2007; Kim et al. 2010; Wang et al. 2011a among many others).

Dispersion plays a significant role in CNT studies as CNTs tend to form bundles due to their fibrous geometry and van der Walls forces. They often form large agglomerates of the order of microns when provided by manufacturers in the powder form (Kim et al. 2010; Wang et al. 2011a). Researchers have developed different methods to disperse CNTs in the aerosol form, including mechanical agitation methods (Maynard et al. 2007; Mitchell et al. 2007; Lee et al. 2009; Myojo et al. 2009), acoustic methods (Baron et al. 2008; McKinney et al. 2009), atomizers (Lee et al. 2009; Seto et al. 2010), and electrosprays (Ku 
and Kulkarni 2009; Jennerjohn et al. 2010). We have experiences in aerosolizing CNTs for toxicological studies (Kim et al. 2010). We have developed dispersion techniques using an electrospray to generate airborne CNTs with controlled degree of agglomeration. A large amount of CNTs can be generated for testing of high efficiency filters.

Filtration is one of the primary technologies for nanoparticle control (Wang et al. 2011a). Multi-wall CNTs may have dimensions similar to asbestos fibers, on which significant filtration research has been performed (Feigley 1975; Gallily et al. 1986; Spurny 1986; Gentry et al. 1989; Gradoń et al. 1988, 1989; Gradoń and Podgórski 1990; Feigley and Chen, 1992; Myojo 1999; Cheng et al. 2006; Webber et al. 2007; Vallero et al. 2009). The deposition of fibers in human airway has also attracted substantial interests from researchers (Morgan et al. 1980; Gurman et al. 1984a, b; Lippmann 1990; Cheng 1995; Su and Cheng 2005). The studies showed that the fiber axial alignment and aerodynamic diameter are pivotal for lung deposition.

A limited number of studies have been devoted to the transport and filtration of CNTs in aqueous solutions through porous media (Jaisi et al. 2008; Jaisi and Elimelech 2009; Liu et al. 2009). The studies on filtration of CNTs in air where they have high mobility are scarce (Seto et al. 2010; Wang et al. 2011b). Our capability of generating a large amount of airborne CNTs facilitates filtration studies. We have measured penetration of multi-wall CNTs through a metal screen filter. Wang et al. (2011b) reported the experimental results and carried out a three-dimensional numerical simulation for CNT penetration through the screen, which gave results in reasonable agreement with the experimental ones. More experimental details and characterization data of the airborne CNTs from the electrospray are presented in this article. The same experimental results for CNT penetration are analyzed in this article using the single-fiber filtration theories. Compared with the numerical simulation approach as in Wang et al. (2011b), the single-fiber analysis provides an easier and a faster alternative. The analysis revealed the dependence of penetration on the CNT aerodynamic diameter which will be discussed in detail in the "Results" section.

Our experimental method involved classifying aerosols with a Differential Mobility Analyzer (DMA) and measuring filtration efficiency for monodisperse particles with the same electrical mobility. We have employed this approach to study filtration of nanoparticles down to $3 \mathrm{~nm}$ (Kim SC et al. 2007; Wang et al. 2007), penetration by means of nanofiber composite filters (Wang et al. 2008a, b), and filtration of nanoparticle agglomerates (Kim SC et al. 2009). This approach led to consistent results and easier data analysis compared with filtration tests using polydisperse aerosols.

\section{Experimental setup}

Figure 1 illustrates the CNT filtration measurement system, which consisted of a CNT generation system, a size classification system, and a penetration measurement system. Multi-wall CNTs (MWCNTs) manufactured by Mitsui Co., Japan were used in the experiments. The CNTs were dispersed into airborne form using a high through-put electrospray (Kim et al. 2010). To achieve high throughput, a large capillary (ID $2.0 \mathrm{~mm}$, OD $3.2 \mathrm{~mm}$ ), high suspension flow rate (up to $9 \mathrm{~mL} / \mathrm{hr}$ ), and a focusing shield with sheath air were used in the electrospray. The focusing shield (ID $6.35 \mathrm{~mm}$ ) narrowed the spray angle and reduced particle loss on the chamber wall (Fig. 1). Four Po-210 sources (185 MBq each) were installed in the neutralization chamber to minimize electrostatic particle losses. The locations of radioactive sources in the neutralization chamber were carefully chosen to ensure that the entire charge-reduction zone was covered by $\alpha$ particles emitted from the sources while not allowing ions of opposite polarity of the applied voltage to travel upward to reach the spray capillary. This reduced the possibility of neutralization of the highly charged liquid meniscus surface at the tip of the spray capillary, therefore, minimizing the potential interference of the spray process.

The droplets generated by the electrospray can be smaller and more monodisperse compared with those generated by conventional nebulizers such as the Collison atomizer (Kim et al. 2010). Thus, the number of MWCNTs in a single droplet from the electrospray is very limited. In addition, the droplets near the electrospray nozzle are highly charged with the same polarity which effectively reduces the possibility of droplet agglomeration. Owing to these reasons, the electrospray is suitable 
Fig. 1 The experimental system for CNT filtration tests

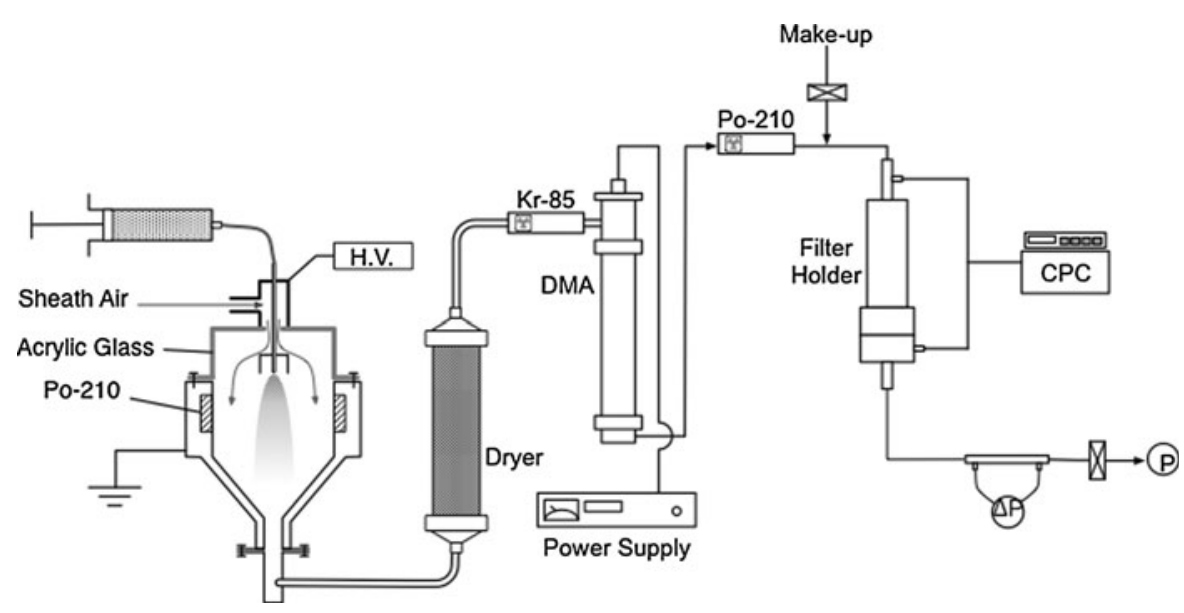

for generating well-dispersed airborne CNTs without large agglomerates.

The MWCNTs from the electrospray went through a diffusion dryer ensuring that liquid vapors were removed. They passed through a $\mathrm{Kr}-85$ neutralizer and were then classified by a DMA (TSI 3081) to achieve CNTs with the same electrical mobility size. The monodisperse CNTs then went through a Po-210 neutralizer to acquire Boltzmann equilibrium charging status. The CNTs were mixed with make-up air and employed to challenge the filter. The number concentrations upstream and downstream of the filter were measured by a Condensation Particle Counter (CPC). Then, the fractional penetration through the filter was obtained. A laminar flow element was utilized in the downstream of the filter to monitor the flowrate, which in turn determined the face velocity for the filter. CNTs penetrating through the testing filter were removed by a high efficiency filter before the flow went into the vacuum pump.

The testing filters were screens made of 635-mesh type 304 stainless steel, which were utilized in the diffusion battery (TSI, model 3040). The screen wire was $20 \mu \mathrm{m}$ in diameter and the opening dimension was also $20 \mu \mathrm{m}$. The screen was well characterized by several studies including Sinclair et al. (1979), Cheng and Yeh (1980), and Wang et al. (2011b). The solidity $\alpha$, which is the solid fraction in the filter compared with the total volume, is 0.345 as measured by Cheng and Yeh (1980) using a gravimetric method. The main reason we chose the wire mesh screen was that it had a regular structure with welldefined wire diameter and opening dimension.

\section{Results}

Characterization of electrosprayed CNTs

The electrosprayed MWCNTs can be characterized in the airborne form or collected on substrates for subsequent electron microscopic analysis. Kim et al. (2010) measured the electrosprayed MWCNTs using a Scanning Mobility Particle Sizer (SMPS) and showed that the size distribution had peaks around 150 and $400 \mathrm{~nm}$, even though the geometric lengths were $2-10 \mu \mathrm{m}$. Similar results have been observed by Lee et al. (2009) and Seto et al. (2010) for MWCNTs aerosolized by atomizers. We utilized the DMA to select CNTs of a certain mobility diameter and deposited them on a piece of silicon wafer placed inside a Nanometer Aerosol Sampler (NAS, TSI 3089), and then analyzed them using Scanning Electron Microscopy (SEM). The NAS utilized an electrical field enhancing deposition of charged particles. Figure 2 shows an example of SEM images of CNTs collected at the edge of the grid. Many CNTs were deposited near the edge of the grid because the electrical field was strong there.

A large number of CNTs were measured from the SEM images and the length distribution was fitted into a lognormal distribution. The mean length of the CNTs was then obtained for the corresponding mobility diameter. Figure 3 shows the CNT number count versus the geometric length for mobility diameters of 200, 300, and $400 \mathrm{~nm}$. The results in our study showed that the mean CNT lengths were 2300, 4300, and $6100 \mathrm{~nm}$ when the CNT mobility diameter was 200, 300, and $400 \mathrm{~nm}$, respectively. 

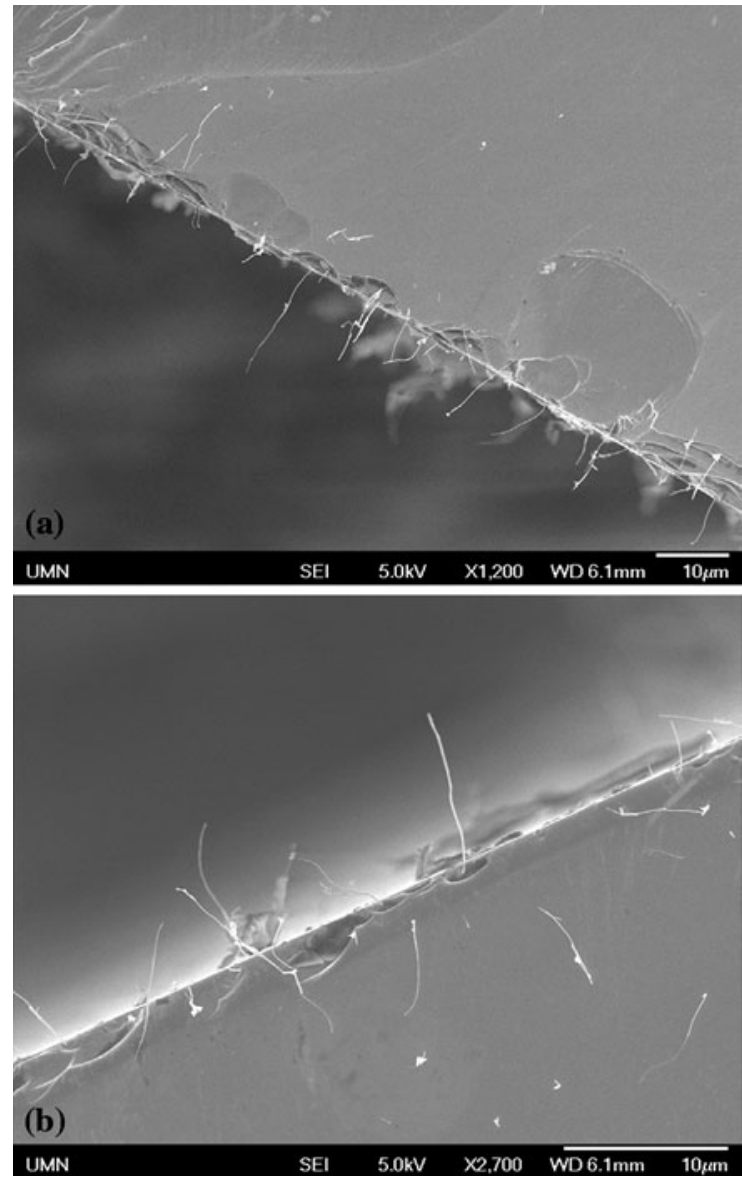

Fig. 2 Examples of the SEM images of the electrosprayed CNTs collected at the edges of the pieces of silicon wafers

The diameter of the CNTs was $d_{C N T}=85 \mathrm{~nm}$ in all cases. Seto et al. (2010) showed that the fractions of multiply charged particles were 29 and $20 \%$ for 200 and $300 \mathrm{~nm}$ CNTs, respectively. Our CNT length distributions (Fig. 3) had distinctively single modes, thus we believe that the fractions of multiply charged particles in this study were relatively low.

Wang et al. (2011b) fitted the experimental data into the relation between the geometric length $L_{C N T}$ and electrical mobility diameter $d_{m}$ of nanotubes given by $\mathrm{Kim} \mathrm{SH}$ et al. (2007) and obtained

$L_{C N T}=21.447 \frac{d_{m}}{C_{c}\left(d_{m}\right)}$

where $C_{c}$ is the Cunningham slip correction factor. Equation 1 is employed to compute the CNT length in this study.

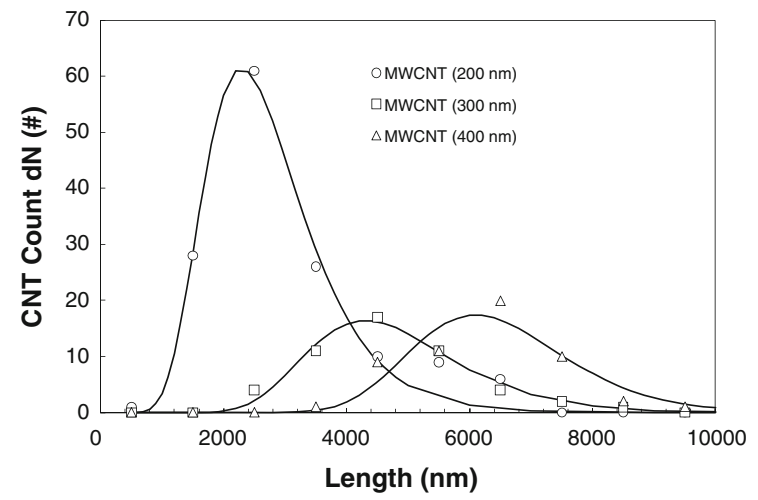

Fig. 3 The CNT number count versus the geometric length measured from SEM images for mobility diameters of 200 , 300 , and $400 \mathrm{~nm}$. The curves represent lognormal fitting for the data of each mobility size

We tested the stability of the concentration of airborne CNTs generated by the electrospray. We fixed the operation conditions of the electrospray, changed the DMA voltage to select CNTs of different sizes, and monitored the airborne CNT concentration for extended duration. Figure 4 shows the CNT number concentration as a function of time. Different mobility sizes, $80,100,150,200$, and $300 \mathrm{~nm}$ were selected, and the concentration for each size was rather stable over several hundred seconds. The results demonstrate that our electrospray produced airborne CNTs with stable concentration, which was very important for reliable filtration results. The results also show that the CNT number-size distribution had the peak around $200-300 \mathrm{~nm}$, which is consistent with the SMPS results obtained by Kim et al. (2010).

\section{Penetration test results}

The penetration of CNTs and Polystyrene Latex (PSL) particles was measured through 20 layers of the diffusion screens. The face velocity was $5 \mathrm{~cm} / \mathrm{s}$ in the experiments. Since the filtration efficiency of a single screen was very low, 20 layers were used to improve the measurement statistics. The PSL particles were employed to provide the control data set. Figure 5 shows the measured penetration values of CNTs and PSL spheres as functions of the mobility size. When the mobility size was above $100 \mathrm{~nm}$, the penetration of CNTs was considerably lower than that of PSL spheres. In the range of $100-400 \mathrm{~nm}$, 


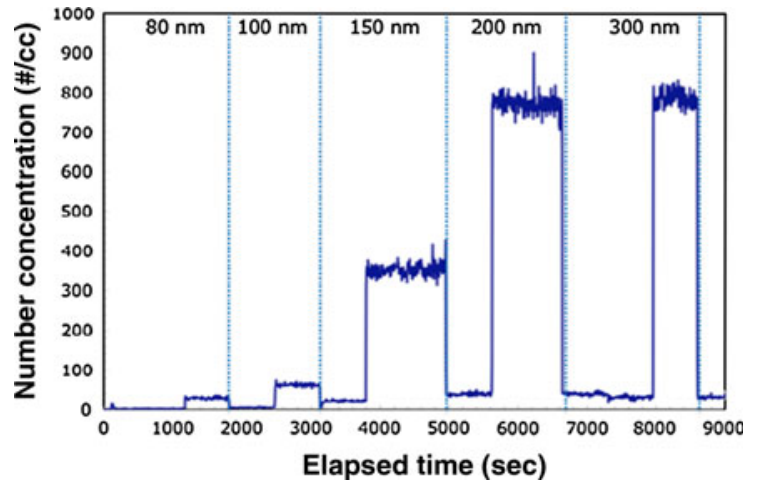

Fig. 4 Concentrations of CNTs generated by the electrospray and classified by the DMA were stable over several hundred seconds

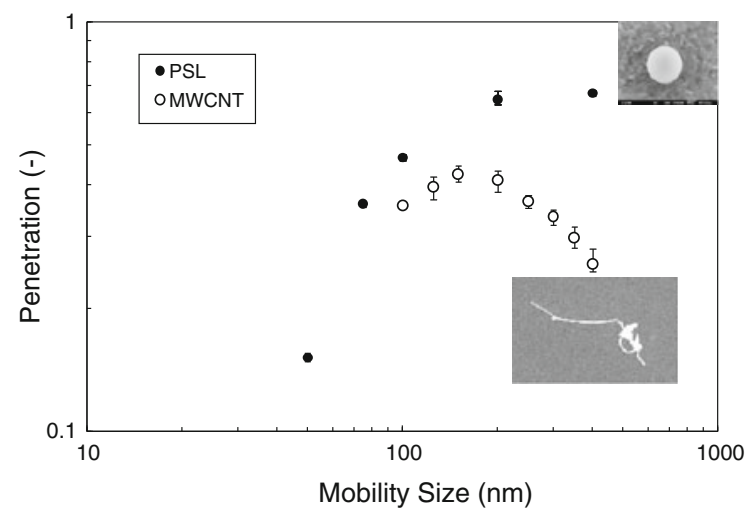

Fig. 5 The measured penetration values of MWCNTs and PSL spheres as functions of the mobility size through 20 layers of the screen filter. The error bars are the standard deviation of the data from five repeated penetration experiments

filtration is dominated by diffusion and interception mechanisms (Lee and Liu 1982). The capture efficiency due to diffusion is similar for spherical particles and elongated particles with the same electrical mobility size (Kim SC et al. 2009). Therefore, interception was the main mechanism that gave the difference between the penetrations of the spheres and the CNTs.

Wang et al. (2011b) used a three-dimensional numerical model to simulate CNT penetration through screen filters. They considered the effects of CNT rotation and orientation on the drag, diffusion coefficient and interception length. In this article, we consider the penetration results in the frame of the single-fiber filtration theory. The advantage of the current approach is that the calculation can be carried out easily with spreadsheet software. Mechanisms for particle capture include diffusion, interception, inertial impaction, and gravitational settling. Gravitational settling is usually negligible for nanoparticles and calculation by Seto et al. (2010) confirmed this for CNTs. The single-fiber efficiency due to diffusion $\left(E_{D}\right)$ may be written as

$E_{D}=2.7 P e^{-2 / 3}$

where

$P e=\frac{d_{f} U_{0}}{D}=d_{f} U_{0} \frac{3 \pi \mu}{k T C_{c}} d_{p}$.

In the equations, $P e$ is the Peclet number, $d_{f}=20 \mu \mathrm{m}$ is the wire diameter in the screen, $U_{0}$ is the face velocity, $D$ is the particle diffusion coefficient, $\mu$ is the air viscosity, $k$ is the Boltzmann constant, $T$ is the temperature, and $d_{p}$ is the particle diameter. Equation 2 was shown to be reasonable for the screen-type diffusion battery by Cheng and Yeh (1980) using experimental data of $\mathrm{NaCl}$ and DOP particles. Since the diffusion coefficient can be directly related to the electrical mobility (Wang et al. 2011b), $d_{p}$ in Eq. 3 can be approximated using the mobility diameter of the CNTs.

The single-fiber efficiency due to interception $\left(E_{R}\right)$ of spherical particles can be written as (Lee and Liu 1982)

$$
\begin{aligned}
E_{R}= & \frac{1+R}{2 K u}\left[2 \ln (1+R)-1+\alpha+\left(\frac{1}{1+R}\right)^{2}\right. \\
& \left.\times\left(1-\frac{\alpha}{2}\right)-\frac{\alpha}{2}(1+R)^{2}\right]
\end{aligned}
$$

where

$R=d_{p} / d_{f}$

and

$K u=-0.5 \ln \alpha-0.75-0.25 \alpha^{2}+\alpha$.

In the equations, the solidity $\alpha=0.345$ and $K u$ is the Kuwabara hydrodynamic parameter. The choice of $d_{p}$ in Eq. 5 is very important for the calculation results and will be discussed in detail in the following part.

The efficiency due to inertial impaction $\left(E_{I}\right)$ can be expressed as (Wang and Pui 2009) 
$E_{I}=\frac{1}{(2 K u)^{2}}\left[\left(29.6-28 \alpha^{0.62}\right) R^{2}-27.5 R^{2.8}\right] \mathrm{Stk}$

where Stk is the Stokes number. For spherical particles,

$\mathrm{Stk}=\frac{\rho_{p} d_{p}^{2} C_{c} U_{0}}{18 \mu d_{f}}$,

where $\rho_{p}$ is the particle density. For CNTs, we apply the method used by Spurny (1986). He wrote that the aerodynamic radius $R_{\mathrm{ae}}$ of a fibrous particle depended on the aspect ratio $\beta\left(=L_{\mathrm{CNT}} / d_{\mathrm{CNT}}\right)$ and the orientation angle $\psi$ between the major axis of the fibrous particle and the direction of motion. For a parallel fiber orientation within the gas flow

$R_{\mathrm{ae} 1}=\frac{d_{\mathrm{CNT}} \beta}{3[\ln (2 \beta)-0.5]}$

and for a perpendicular orientation

$R_{\mathrm{ae} 2}=\frac{2 d_{\mathrm{CNT}} \beta}{3[\ln (2 \beta)+0.5]}$

and for a random orientation

$R_{\mathrm{ae}}=R_{\mathrm{ae} 1} \sin ^{2} \psi+R_{\mathrm{ae} 2} \cos ^{2} \psi$.

The angle $\psi$ takes the value $54.74^{\circ}$ when the orientation is random ( $\mathrm{Fu}$ et al. 1990). Then the Stokes number for CNTs can be computed as

$\mathrm{Stk}=\frac{d_{\mathrm{CNT}}^{3} \rho_{\mathrm{CNT}} U_{0}}{18 \mu d_{f} R_{\mathrm{ae}}}$.

Kim SH et al. (2009) reported that the density of size-selected multi-wall CNTs was $\rho_{\mathrm{CNT}}=1.74 \mathrm{~g} /$ $\mathrm{cm}^{3}$ measured by a mobility-mass method. The parameter $R$ in Eq. 7 is used for calculating the initial impaction effect, therefore, we use the aerodynamic size to compute it: $R=2 R_{\mathrm{ae}} / d_{f}$.

An additional interaction term, $E_{D R}$, may be added to the single-fiber efficiency, to account for interception of particles undergoing diffusion. An explicit expression for $E_{D R}$ has been given for spherical particles (Hinds 1999)

$E_{D R}=\frac{1.24 R^{2 / 3}}{(\mathrm{Ku} \cdot \mathrm{Pe})^{1 / 2}}$.

The applicability of this expression for elongated particles is not known. Nonetheless, we apply Eq. 13 to CNTs in this study. The definition of $R$ in Eq. 13 is the same as in Eq. 5. The choice of $d_{p}$ is important for both $E_{D}$ and $E_{D R}$, and to a large extend dictates the agreement between the calculation results and the experimental ones.

The total single-fiber efficiency is computed as

$E_{T}=E_{D}+E_{I}+E_{R}+E_{D R}$,

and penetration of the filter is computed as

$P=\exp \left(-\frac{4 \alpha E_{T} t}{\pi d_{f}(1-\alpha)}\right)$.

In this equation, $t$ is the thickness of 20 layers of the screen filter. We compare the computed penetration values with the experimental ones in Fig. 6. It can be seen that the agreement for the PSL particles is very good. It demonstrates that the expressions for single-fiber efficiencies listed above work well in the case of spherical particles and a filter with very regular structures. For the CNTs, we performed the calculation with three different options for the value of $d_{p}$ in Eq. 5. The geometric length of the CNTs may be utilized for $d_{p}$ in calculation of the interception parameter $R$. This approach is plausible if the particle's rotation time is much less than the time for the particle to pass by a screen wire. Kim SC et al. (2009) employed the maximum geometric length to calculate the interception parameter for silver agglomerates in their filtration studies and obtained reasonable results. The aspect ratio of the silver

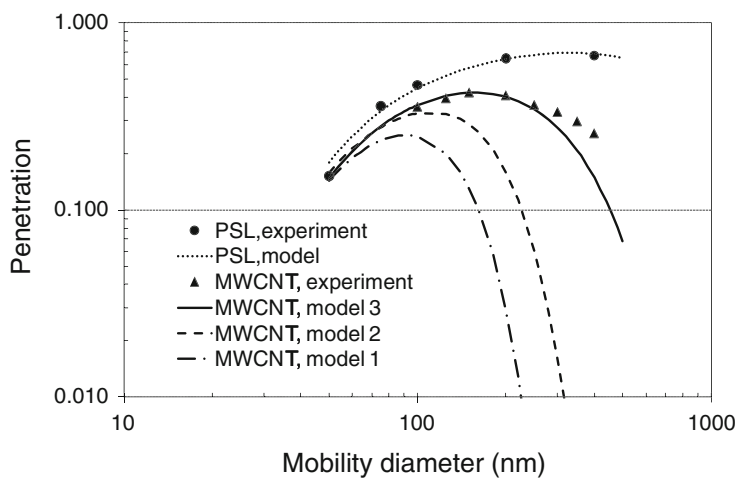

Fig. 6 Penetration as a function for PSL particles and MWCNTs. The symbols are experimental results and the curves are modeling results. Three models are used for MWCNTs. In model $1, L_{C N T}$ is used for the interception effect; in model $2, L_{C N T} \times \sin \theta\left(\theta \approx 40^{\circ}\right)$ is used for the interception effect; in model $3,2.4 \times\left(2 R_{\mathrm{ae}}\right) \times \sin \theta\left(\theta \approx 40^{\circ}\right)$ is used for the interception effect 
agglomerates was in the range of 1.6-1.8, thus their rotation time was short. In contrast, the CNTs in this study had aspect ratios in the range of 10-70. Wang et al. (2011b) showed that the rotation time of such CNTs can be much longer than the time for the CNTs to pass by a screen wire. Therefore, the approach to use the CNT geometric length to compute the interception parameter does not give satisfactory results. Figure 6 shows the penetration computed with this approach is significantly lower than that of the experimental value.

In the second approach, we consider the orientation angle $\theta$ between the CNT and the screen wire surface. Wang et al. (2011b) assumed that the CNT orientation was random and obtained the average orientation angle $\theta$ which was about $40^{\circ}$. It follows that $L_{C N T} \times \sin \theta \approx 0.63 L_{C N T}$ should be used for the value of $d_{p}$ in Eq. 5. The penetration computed with this approach is only close to experimental values when the CNT mobility diameter is close to $100 \mathrm{~nm}$. For longer CNTs, the calculation underestimates the penetration substantially. Several factors may contribute to the underestimation. One reason may be that the expression for the interaction term, $E_{D R}$, was developed for spheres and not applicable for elongated particles. Another reason may be that longer CNTs curl or bend in the flow, which makes their effective interception length smaller and easier to penetrate the filter. Wang et al. (2011b) suggested that curling or bending of long CNTs may occur. Gradoń and Podgórski (1990) showed that perfectly flexible elongated particles can deform and align with the streamline and pass by the filter element, which agree qualitatively with our reasoning.

In the third approach, we attempt to fit the modeling results to experimental data by varying the interception parameter. We find applying 2.4 times the aerodynamic diameter $2 R_{\mathrm{ae}}$ and the orientation angle $\theta \approx 40^{\circ}$ gives rise to a good agreement. The curve for model 3 in Fig. 6 represents the modeling results when $2.4 \times\left(2 R_{\mathrm{ae}}\right) \times \sin \theta$ is used for the value of $d_{p}$ in Eq. 5. This agreement appears to be fortuitous because the aerodynamic diameter is related to the drag force on a particle during its motion, whereas, we should use an interception length which is related to the distance from the center of mass and the wire surface. A scaling factor of 2.4 needs to be used, indicating that the aerodynamic diameter is indeed different from the interception length. The penetration curve computed with the third approach does not make a steep downturn for long CNTs, which is quite different from the other two modeling approaches and similar to the trend shown by the experimental data. We hypothesize that this is because the long CNTs deform in the flow and become more compact, which leads to a smaller interception length compared with the length of the original straight CNTs $L_{C N T}$. The ratio between the interception length and $L_{C N T}$ is smaller for longer CNTs, since longer CNTs are more susceptible to deformation. On the other hand, the ratio between the aerodynamic diameter and $L_{C N T}$ is proportional to $1 / \ln (2 \beta)$, when $\beta$ is much larger than one. This ratio is also getting smaller for longer CNTs, and it seems that the ratio is approximated proportional to the ratio between the interception length and $L_{C N T}$.

The MWCNT filtration experiments of Seto et al. (2010) provide another set of data to test the above hypothesis. Seto et al. compared their experimental results with the single-fiber efficiency assuming that interception was the dominant mechanism. They concluded that an orientation angle, $\theta$, was needed to match the experimental and modeling results. The effective interception length was given by $\sin \theta$ multiplying the CNT length. We have listed the data from Seto et al. at the face velocities of 5 and $10 \mathrm{~cm} / \mathrm{s}$ in Table 1. The effective interception lengths and aerodynamic diameters are computed, and their ratios are approximately constant, about 3.45 for $5 \mathrm{~cm} / \mathrm{s}$ and 3.3 for $10 \mathrm{~cm} / \mathrm{s}$, respectively. This demonstrates that the interception length may be approximated by the aerodynamic length multiplying a scaling factor, in accordance with our observation. The scaling factor seems to be dependent on the face velocity and type of the CNTs. The data by Seto et al. (2010) at higher face velocities $(15-50 \mathrm{~cm} / \mathrm{s})$ led to non-monotonic values for $\theta$, and thus cannot agree with our hypothesis. We conjecture that it may be related to omission of other filtration mechanisms including impaction in the analysis by Seto et al.

\section{Conclusion}

We generated MWCNTs with a home-made electrospray system. The size, concentration, and stability of the aerosolized CNTs were characterized by DMA, 
Table 1 Calculation for the interception length and aerodynamic diameter based on the data of Seto et al. (2010)

\begin{tabular}{lllllcll}
\hline$U_{0}(\mathrm{~cm} / \mathrm{s})$ & $d_{m}(\mathrm{~nm})$ & $L_{C N T}(\mathrm{~nm})$ & $\beta$ & $\theta\left(^{\circ}\right)$ & Interception $d_{p}(\mathrm{~nm})$ & $2 R_{\mathrm{ae}}(\mathrm{nm})$ & Interception $d_{p} /\left(2 R_{\mathrm{ae}}\right)$ \\
\hline 5 & 100 & 1100 & 20.4 & 59 & 943 & 269 & 3.51 \\
& 200 & 1300 & 22.8 & 53 & 1038 & 308 & 3.37 \\
10 & 300 & 2100 & 36.8 & 47 & 1536 & 440 & 3.49 \\
& 100 & 1100 & 20.4 & 53 & 878 & 269 & 3.27 \\
& 200 & 1300 & 22.8 & 52 & 1024 & 308 & 3.33 \\
\hline
\end{tabular}

CPC, and SEM. We measured the penetration of MWCNTs through a screen filter as a function of the mobility diameter. The results showed that the CNT penetration was less than the penetration for a sphere with the same mobility diameter. We compared the modeling results using single-fiber efficiency theories with the experimental data, and found that the effective interception length can be approximated by the CNT aerodynamic diameter multiplying a scaling factor. This result seems to be fortuitous but provides an interesting approach for computing the penetration of elongated particles with large aspect ratios. We hypothesize that deformation of the long particles in the flow may lead to reduced interception length, which happens to be proportional to the aerodynamic diameter. Further studies on deformation of elongated particles in flows are necessary to assess this hypothesis.

Acknowledgments This study was partially supported by the NSF grant (Award ID: 1056479) on "Real Time Measurement of Agglomerated or Aggregated Airborne Nanoparticles Released from a Manufacturing Process and Their Transport Characteristics". The authors would like to thank the support of the members of the Center for Filtration Research: 3M Corporation, Boeing Company, Cummins Filtration Inc., Donaldson Company Inc., Entegris Inc, Hollingsworth \& Vose Company, Samsung Semiconductor Inc., Shigematsu Works CO., LTD, TSI Inc., W. L. Gore \& Associates, and the affiliate member National Institute for Occupational Safety and Health (NIOSH).

\section{References}

Baron PA, Deye GJ, Chen BT, Schwegler-Berry DE, Shvedova AA, Castranova V (2008) Aerosolization of single-walled carbon nanotubes for an inhalation study. Inhalation Toxicol 20:751-760

Cheng YS (1995) Deposition of ultrafine aerosols and thoron progeny in replicas of nasal airways of young-children. Aerosol Sci Technol 23:541-552
Cheng YS, Yeh HC (1980) Theory of a screen-type diffusion battery. J Aerosol Sci 11:313-320

Cheng YS, Holmes TD, Fan B (2006) Evaluation of respirator filters for asbestos fibers. J Occup Environ Hyg 3(1):26-35

Feigley CE (1975) A mathematical model for deposition of asbestos in fibrous filter. Clean Air 9(4):67-71 (Heidelberg, Aust.)

Feigley CE, Chen HC (1992) Penetration of several filter materials by asbestos as a function of fiber dimensions. Am Ind Hyg Assoc J 53(12):767-772

Fu TH, Cheng MT, Shaw DT (1990) Filtration of chain agglomerate aerosols by model screen filter. Aerosol Sci Technol 13:151-161

Gallily I, Schiby D, Cohen AH, Hollander W, Schless D (1986) On the Inertial separation of nonspherical aerosol particles from laminar flows. I. The cylindrical case. Aerosol Sci Tech 5:267-286

Gentry GW, Spurny K, Schörmann D (1989) Collection efficiency of ultrafine asbestos fibers, experimental and theory. Aerosol Sci Technol 9:184

Gradoń L, Podgórski A (1990) Flexible fibrous particle behaviour in the carrier gas flow around cylindrical obstacle. Chem Eng Sci 45:3435

Gradoń L, Grzybowski P, Piłaciński W (1988) Analysis of motion and deposition of fibrous particles on a single filter element. Chem Eng Sci 43:1253-1259

Gradoń L, Podgórski A, Grzybowski P (1989) Deposition of flexible and stiff fibrous particles. J Aerosol Sci 20: 971-974

Gurman JL, Lioy PJ, Lippmann M, Schlesinger RB (1984a) Particle deposition in replicate casts of the human upper tracheobronchial tree under constant and cyclic inspiratory flow. II. Empirical model. Aerosol Sci Technol 3:253-257

Gurman JL, Lippmann M, Schlesinger RB (1984b) Particle deposition in replicate casts of the human upper tracheobronchial tree under constant and cyclic inspiratory flow. I. Exp Aerosol Sci Technol 3:245-252

Helland A, Wick P, Koehler A, Schmid K, Som C (2007) Reviewing the environmental and human health knowledge base of carbon nanotubes. Environ Health Perspect 115:1125-1131

Hinds WC (1999) Aerosol technology: properties, behavior, and measurement of airborne particles, 2nd edn. WileyInterscience, New York

Jaisi DP, Elimelech M (2009) Single-walled carbon nanotubes exhibit limited transport in soil columns. Environ Sci Technol 43(24):9161-9166 
Jaisi DP, Saleh NB, Blake RE, Elimelech M (2008) Transport of single-walled carbon nanotubes in porous media: filtration mechanisms and reversibility. Environ Sci Technol 42(22):8317-8323

Jennerjohn N, Eiguren-Fernandez A, Prikhodko S, Fung DC, Hirakawa KS, Zavala-Mendez JD, Hinds W, Kennedy NJ (2010) Design, demonstration and performance of a versatile electrospray aerosol generator for nanomaterial research and applications. Nanotechnology 21:255603

Kim SC, Harrington MS, Pui DYH (2007) Experimental study of nanoparticles penetration through commercial filter media. J Nanopart Res 9:117-125

Kim SH, Mulholland GW, Zachariah MR (2007) Understanding ion-mobility and transport properties of aerosol nanowires. J Aerosol Sci 38:823-842

Kim SC, Wang J, Emery M, Shin W-G, Mullholand G, Pui DYH (2009) Structural property effect of nanoparticle agglomerates on particle penetration through fibrous filter. Aerosol Sci Technol 43(4):344-355

Kim SH, Mulholland GW, Zachariah MR (2009) Density measurement of size selected multiwalled carbon nanotubes by mobility-mass characterization. Carbon 47(5):1297-1302

Kim SC, Chen DR, Qi C, Gelein RM, Finkelstein JN, Elder A, Bentley K, Oberdorster G, Pui DYH (2010) A nanoparticle dispersion method for in vitro and in vivo nanotoxicity study. Nanotoxicology 4(1):42-51

Ku BK, Kulkarni P (2009) Morphology of single-wall carbon nanotube aggregates generated by electrospray of aqueous suspensions. J Nanopart Res 11:1393-1403

Lee KW, Liu BYH (1982) Theoretical study of aerosol filtration by fibrous filters. Aerosol Sci Technol 1:147-161

Lee S-B, Lee J-H, Bae G-N (2009) Size response of an SMPSAPS system to commercial multi-walled carbon nanotubes. J Nanopart Res 12:501-512

Lippmann M (1990) Effects of fiber characteristics on lung deposition, retention and disease. Environ Heath Perspect 88:311-317

Liu X, O'Carroll DM, Petersen EJ, Huang Q, Anderson CL (2009) Mobility of multiwalled carbon nanotubes in porous media. Environ Sci Technol 43(21):8153-8158

Maynard AD, Ku BK, Emery M, Stolzenburg M, McMurry PH (2007) Measuring particle size-dependent physiochemical structure in airborne single walled carbon nanotube agglomerates. J Nanopart Res 9:85-92

McKinney W, Chen BT, Frazer D (2009) Computer controlled multi-walled carbon nanotube inhalation exposure system. Inhalation Toxicol 21:1053-1061

Mitchell L, Gao J, Vander Wal R, Gigliotti A, Burchiel S, McDonald J (2007) Pulmonary and systemic immune response to inhaled multiwalled carbon nanotubes. Toxicol Sci 100:203-214
Morgan A, Black A, Evans N, Holmes A, Pritchard JN (1980) Deposition of sized glass fibers in the respiratory tract of the rat. Ann Occup Hyg 23:353-366

Myojo T (1999) A simple method to determine the length distribution of fibrous aerosols. Aerosol Sci Technol 30:30-39

Myojo T, Oyabu T, Nishi K, Kadoya C, Tanaka I, Ono-Ogasawara M, Sakae H, Shirai T (2009) Aerosol generation and measurement of multi-wall carbon nanotubes. J Nanopart Res 11:91-99

Seto T, Furukawa T, Otani Y, Uchida K, Endo S (2010) Filtration of multi-walled carbon nanotube aerosol by fibrous filters. Aerosol Sci Technol 44:734-740

Sinclair D, Countess RJ, Liu BYH, Pui DYH (1979) In: Lundgren DA, Lippmann M, Harris FS Jr, Clark WE, Marlow WH, Durham MD (eds) Aerosol Measurement, University Presses of Florida, Gainesville, p 544

Spurny KR (1986) On the filtration of fibrous aerosols. Sci Total Environ 52:189-199

Su W-C, Cheng YS (2005) Deposition of fiber in the human nasal airway. Aerosol Sci Technol 39:888-901

Vallero DA, Kominsky JR, Beard ME, Crankshaw OS (2009) Efficiency of sampling and analysis of asbestos fibers on filter media: implications for exposure assessment. J Occup Environ Hyg 6(1):62-72

Wang J, Pui DYH (2009) Numerical investigation of filtration by fibers with elliptical cross-sections. J Nanopart Res 11(1):185-196

Wang J, Chen DR, Pui DYH (2007) Modeling of filtration efficiency of nanoparticles in standard filter media. J Nanopart Res 9:117-125

Wang J, Kim SC, Pui DYH (2008a) Investigation of the figure of merit for filters with a single nanofiber layer on a substrate. J Aerosol Sci 39:323-334

Wang J, Kim SC, Pui DYH (2008b) Figure of merit of composite filters with micrometer and nanometer fibers. Aerosol Sci Technol 42:722-728

Wang J, Asbach C, Fissan H, Hülser T, Kuhlbusch TAJ, Thompson D, Pui DYH (2011a) How can nanobiotechnology oversight advance science and industry: examples from environmental, health and safety studies of nanoparticles (nano-EHS). J Nanopart Res 13:1373-1387

Wang J, Kim SC, Pui DYH (2011b) Carbon nanotube penetration through a screen filter: numerical modeling and comparison with experiments. Aerosol Sci Technol 45:443-452

Webber JS, Czuhanich AG, Carhart LJ (2007) Performance of membrane filters used for TEM analysis of asbestos. J Occup Environ Hyg 4(10):780-789

Wick P, Manser P, Limbach LK, Dettlaff-Weglikowska U, Krumeich F, Roth S, Stark WJ, Bruinink A (2007) The degree and kind of agglomeration affect carbon nanotube cytotoxicity. Toxicol Lett 168:121-131 